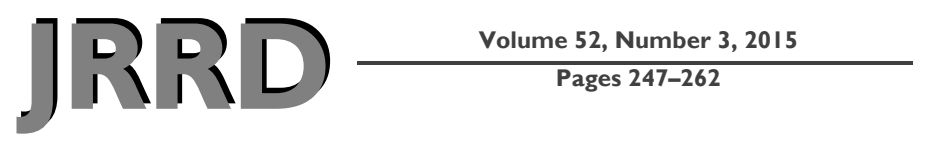

\title{
Differences in myoelectric and body-powered upper-limb prostheses: Systematic literature review
}

\author{
Stephanie L. Carey, PhD; ${ }^{1^{*}}$ Derek J. Lura, PhD; ${ }^{2}$ M. Jason Highsmith, DPT, PhD, CP, FAAOP \\ ${ }^{1}$ Department of Mechanical Engineering, University of South Florida, Tampa, FL; ${ }^{2}$ Department of Bioengineering and \\ Software Engineering, U.A. Whitaker College of Engineering, Florida Gulf Coast University, Fort Myers, FL; ${ }^{3}$ School \\ of Physical Therapy \& Rehabilitation Sciences, Morsani College of Medicine, University of South Florida, Tampa, FL
}

\begin{abstract}
The choice of a myoelectric or body-powered upper-limb prosthesis can be determined using factors including control, function, feedback, cosmesis, and rejection. Although body-powered and myoelectric control strategies offer unique functions, many prosthesis users must choose one. A systematic review was conducted to determine differences between myoelectric and body-powered prostheses to inform evidence-based clinical practice regarding prescription of these devices and training of users. A search of 9 databases identified 462 unique publications. Ultimately, 31 of them were included and 11 empirical evidence statements were developed. Conflicting evidence has been found in terms of the relative functional performance of body-powered and myoelectric prostheses. Body-powered prostheses have been shown to have advantages in durability, training time, frequency of adjustment, maintenance, and feedback; however, they could still benefit from improvements of control. Myoelectric prostheses have been shown to improve cosmesis and phantom-limb pain and are more accepted for light-intensity work. Currently, evidence is insufficient to conclude that either system provides a significant general advantage. Prosthetic selection should be based on a patient's individual needs and include personal preferences, prosthetic experience, and functional needs. This work demonstrates that there is a lack of empirical evidence regarding functional differences in upper-limb prostheses.
\end{abstract}

Key words: amputation, artificial limb, control, cosmesis, external power, function, prosthesis, rehabilitation, transhumeral, transradial.

\section{INTRODUCTION}

In 2005, an estimated 1.6 million people in the United States were living with an amputation. This number is expected to increase to over 2.3 million by 2020 [1]. A more recent report already estimates an increase to 1.7 million people in just over $3 \mathrm{yr}$ [2]. A retrospective study examining amputations sustained by U.S. servicemembers from January 2001 through July 2011 reported that 14 percent of amputations involved the upper limb and that 10 percent of these involved more than one amputation [3]. In 2004, interviews with members of the Amputee Coalition of America found nearly one-third of persons with amputation reported being dissatisfied with

\footnotetext{
Abbreviations: $\mathrm{AAOP}=$ American Academy of Orthotists and Prosthetists, $\mathrm{ADL}=$ activity of daily living, $\mathrm{BP}=$ bodypowered, EES = empirical evidence statement, EMG = electromyography, fMRI = functional magnetic resonance imaging, $\mathrm{MYO}=$ myoelectric, OIF/OEF = Operation Iraqi Freedom $/$ Operation Enduring Freedom, ROM = range of motion, SHAP = Southampton Hand Assessment Procedure, TD = terminal device.

*Address all correspondence to Stephanie L. Carey, PhD; University of South Florida, Department of Mechanical Engineering, 4202 E. Fowler Ave, ENB 118, Tampa, FL 33612; 813-974-5765; fax: 813-974-3539.
}

Email: scarey3@usf.edu

http://dx.doi.org/10.1682/JRRD.2014.08.0192 
the comfort of their device, while 18.4 percent of respondents reported being fit with a new prosthesis at least once a year [4]. Some reports suggest as many as 50 percent of persons with upper-limb amputation choose not to wear a prosthesis [5-6], often citing that the functional advantage or cosmesis did not outweigh the discomfort or inconvenience of the device.

Reports of rejection rates of upper-limb prostheses vary in the literature from 0 to 50 percent [6-14]. According to one source, primary indicators of prosthesis rejection include lack of perceived functional gains, prosthesis weight, and socket discomfort [11], and higher rejection rates correlate with higher amputation levels, congenital limb loss, females, and students [15]. The role of the user in selecting the device and the timeliness of delivery are significant factors in prosthesis acceptance [13]. Even a small change in the artificial limb can have significant effect on the overall body movements [16] and ultimately lead to a reduction in the rate of use of the intact body segments, possibly reducing overuse injuries. Limited function of prostheses may cause awkward aberrant movements not normally experienced by persons without amputation, called compensatory motion [17-18]. These aberrant motions have been cited as one of the factors influencing the discontinuation of prosthetic use [14].

Prosthetic prescription currently depends to varying degrees on patient input, the prosthetist's experience with available components, literature on component function, manufacturer's claims, and reimbursement methods. Availability and prescription of prosthetic components can depend on medical insurance coverage and payer restrictions. Externally powered upper-limb prostheses cost substantially more than body-powered (BP) prostheses [14]. Myoelectric (MYO) prostheses users also incur a higher cost for fitting, training, and maintenance [14]. Major private insurers as well as government health plans limit prosthetic and rehabilitation coverage and require justification to show the necessity of the prosthetic device to restore "normal" function in activities of daily living (ADLs) [2]. Beyond possible payment challenges, it is clear that the two dominant prosthetic choices for persons with upper-limb amputation are the BP and MYO systems $[13,19]$. Because BP and MYO prostheses are the predominant prosthetic options for persons with upper-limb amputation, the purpose of this systematic review was to identify evidence statements regarding differences between them in the following areas: functionality, control and feedback, cosmesis, and rejection that could be used to support the clinical management of persons with upper-limb amputations.

\section{METHODS}

\section{Literature Search}

A systematic search of the literature was conducted in July 2013 using the following databases: PubMed (1947-present), CINAHL (1981-present), RECAL Legacy (1900-2007), Cochrane Database of Systematic Reviews (1992-present), Cochrane Clinical Trials Registry (1992-present), EMBASE (1974-present), PMC-NIH Research Publication Database (2000-present), Web of Science (1900-present), and Google Scholar (early 1900-present). The databases were searched using broad key words related to upper-limb prostheses. The key words were combined into search statements. The following key words were used to search the databases: myoelectric, body-powered, hybrid, externally powered, transradial, transhumeral, upper limb, prosthesis, artificial limbs, voluntary opening, and voluntary closing. A detailed description of model statements are described in Hafner [20]. EndNote bibliographic software, (version X6, Thomson Reuters; Philadelphia, Pennsylvania) was utilized to build the reference library. Additional articles extracted from authors' knowledge of literature in the field, from manually reviewing references of articles identified in the electronic search, and from standard literature email updates were added.

\section{Inclusion and Exclusion Criteria}

Inclusion and exclusion criteria were established in order to select publications that were relevant to the review's purpose statement, which was to compare BP and MYO prostheses to help guide evidence-based clinical decisions. Articles published prior to the search on July 10, 2013, that were editorial, case study/series, observational research designs, experimental research designs, or literature reviews were included. Conference proceedings, white papers, theses, dissertations, progress reports, non-English articles, publications prior to 1993, partial hand/finger articles, surgical articles, modeling articles, pediatric articles, and electromyography (EMG)only articles were excluded from the review. All articles identified by the initial search were reviewed by at least one reviewer to determine whether the article should be reviewed based on the inclusion and exclusion criteria. 
Digital copies were obtained of those articles that met the inclusion criteria for full text review and evaluation.

\section{Assessment of Methodological Quality}

The study design and methodological quality of those publications that met the inclusion and exclusion criteria were independently assessed by at least two of three reviewers according to the protocol developed by the American Academy of Orthotists and Prosthetists (AAOP) state-of-the-science evidence report guidelines [20]. Reviewers discussed pertinent issues until consensus on study design and methodological quality was obtained for the included publications. There were three instances when two of the reviewers were contributing authors to the reviewed publications [17-18,21]. Because of a perceived conflict of interest, the third reviewer assessed the methodological quality of these studies.

Each reviewer rated each study according to the AAOP study design classification scale that describes the type of study design. The state-of-the-science conference quality assessment form was used to rate the methodological quality of studies classified as experimental (E1-E5) or observational (O1-O6). The form identifies 18 potential threats to internal validity, with the first four threats not applicable for study classifications E3-E5 and the first five threats not applicable for classifications O1O6 [20]. Threats were evaluated and tabulated.

Section 6 of the SIGN 50 Methodology Checklist 1: Systematic Reviews and Meta-analyses [22] was used to rate the methodological quality of studies classified as structured reviews (S1-S2). This checklist assesses 11 potential threats to internal validity (section 1 ) and has 3 areas for overall assessment of the study. Based on the results of the checklist, the overall assessment of the study may be scored as high quality, acceptable, or unacceptable. The overall ratings from the AAOP state-ofthe-science evidence report guidelines and from the Methodology Checklist 1 were used in assigning confidence to the developed empirical evidence statements (EESs) described in following section.

\section{Empirical Evidence Statements}

Based on results from the included publications, EESs were developed that compared BP and MYO prostheses. Reviewers rated the level of confidence of each EES as "high," "moderate," "low," or "insufficient" based on the number of publications contributing to the statement, the methodological quality of those studies, and whether the contributing findings were confirmatory or conflicting as similarly outlined by other reviews [23]. Note that in addition to peer-reviewed studies, editorials and systematic reviews were also included to the moderate and low confidence level descriptions because of the lack of observational and experimental studies available in the literature on the topic. In some cases, multiple publications described the same study with the same group of subjects and investigators, and therefore the results of both publications did not strengthen the confidence of the EES derived from the study.

\section{RESULTS}

\section{Literature Search}

The literature search yielded 457 articles. An additional five publications extracted from authors' knowledge of literature in the field and from standard literature email updates were added. Of these 462 unique publications, 418 were excluded after screening the inclusion and exclusion criteria. Forty-four were reviewed and scored for content and quality. Upon further review, an additional 13 articles were excluded because of lack of evidence relevant to the topic, resulting in 31 publications included in the qualitative synthesis (Figure). The included publications spanned the years from 1993 to 2013, with the majority of the publications occurring in 2012. The distribution of the publications selected showed the majority from the Department of Veterans Affairs (VA)sponsored Journal of Rehabilitation Research \& Development, followed closely by two orthotic and prosthetic peer-reviewed journals: Prosthetics and Orthotics International and Journal of Prosthetics and Orthotics.

\section{Study Demographics}

Specific characteristics of the included publications are shown in Table 1. The reviewed studies were classified into 9 of the 15 potential study designs described by the AAOP study design classification scale [20]. The distribution of the studies by study design is shown in Table 2 . Sample sizes ranged from 1 to a maximum of 1,216 adults from one study [27] that surveyed individuals using various types of prostheses. The median subject size was 12 (including case studies). The average age of participants of the reviewed studies that reported subject age was $43.3 \mathrm{yr}$. Outcome measures reported in the reviewed publications included motion analysis, including range of motion (ROM); joint angles during ADLs; kinematics and compensatory motion; reaching/pointing velocity and accuracy; 
Records Identified through database searching PubMed, CINAHL, RECAL Legacy, Cochrane, EMBASE, PMC-NIH, Web of Science, Google

Scholar $(n=457)$
Additional records identified

through other sources

$(n=5)$

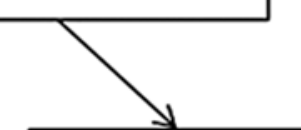

Total Unique Publications

$(\mathrm{n}=462)$
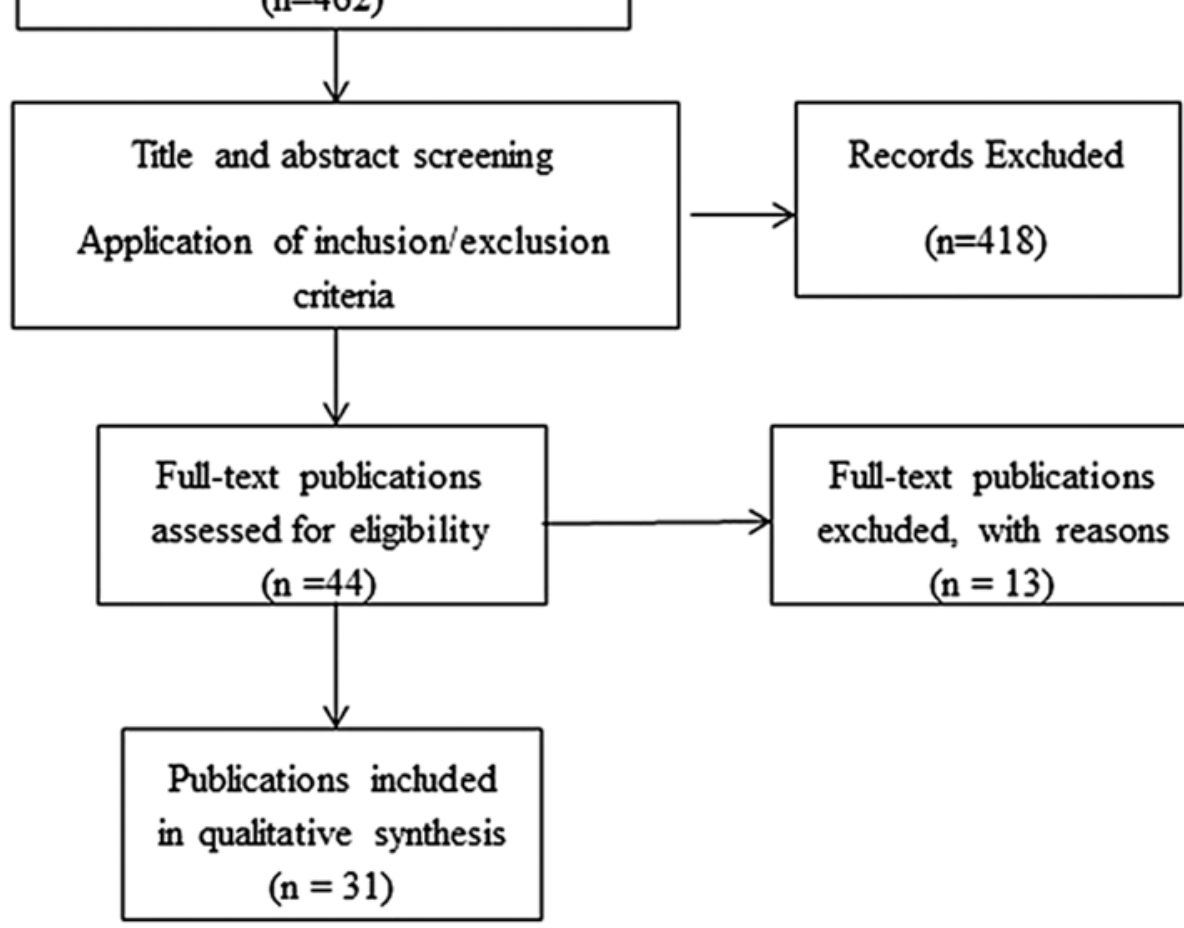

Full-text publications

excluded, with reasons $(\mathrm{n}=13)$

Figure.

Results of literature search and application.

Box and Blocks (and modified); pinch forces; rejection rates; nine hole peg test; the Southampton Hand Assessment Procedure (SHAP); and surveys that included the Trinity Amputation and Prosthesis Experience Scales, the Orthotics and Prosthetics Users Survey, and custom surveys. The majority of the studies (21/31) was declared unfunded or did not specify funding.

\section{Outcome Measures for Assessment of Upper Limb}

A wide variety of outcome measures were used in the assessment of upper-limb prostheses. In the included articles, there were very few measures repeated in multiple studies (Table 1). Assessments tended to fall into three categories: (1) surveys, (2) laboratory and clinical functional assessments, or (3) analysis of use and ability to perform ADLs. Of the 31 included studies, 24 were experimental or observational and included information on the study methods.

Surveys were the most common assessment, used in 12 of the 24 relevant included articles. The majority of surveys were modified or designed for the study and were not used in multiple studies, making it difficult to make direct comparisons. Functional and laboratory assessments were the next most common methods of 
Table 1.

Characteristics of included studies.

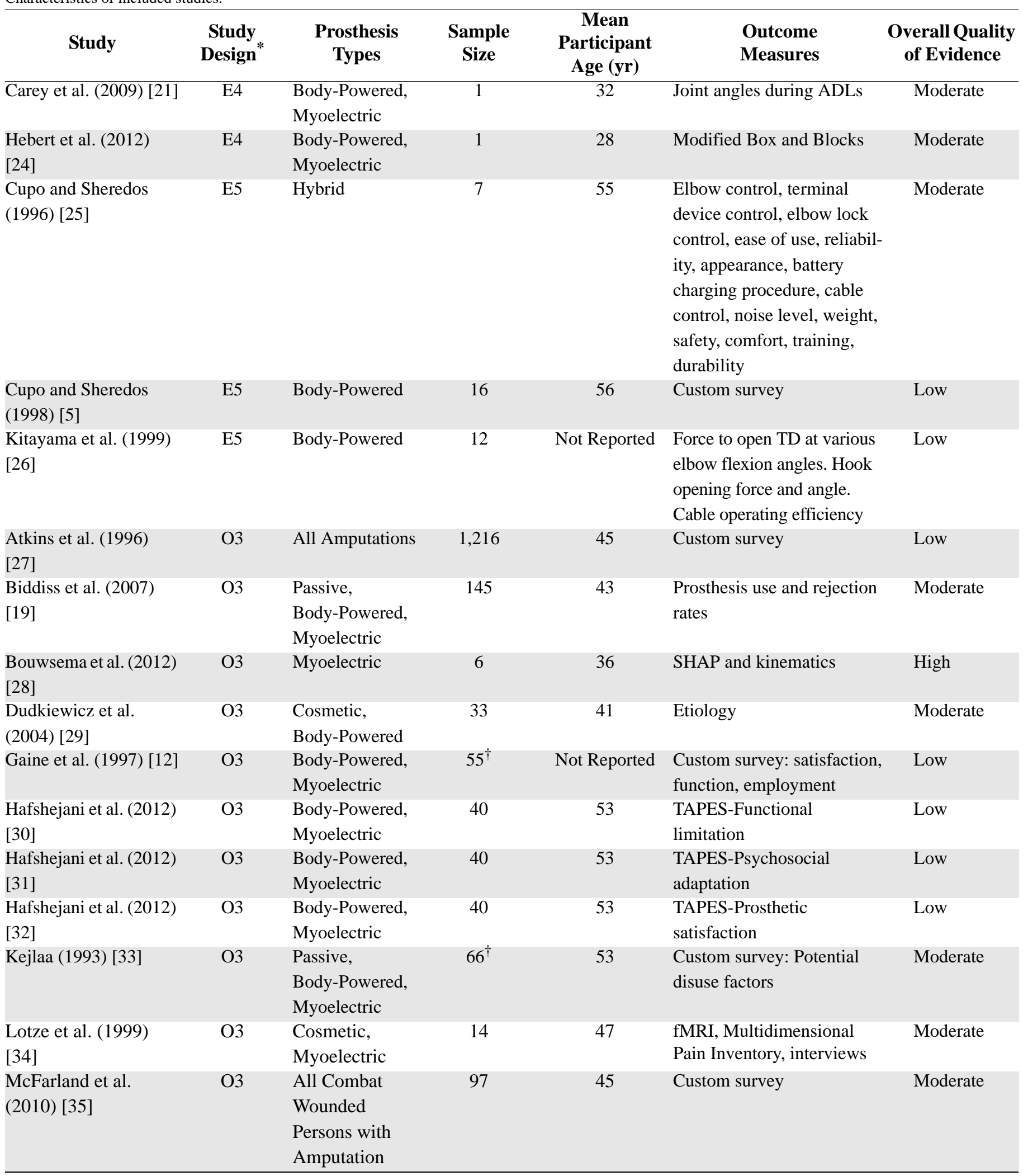


JRRD, Volume 52, Number 3, 2015

Table 1. (cont)

Characteristics of included studies.

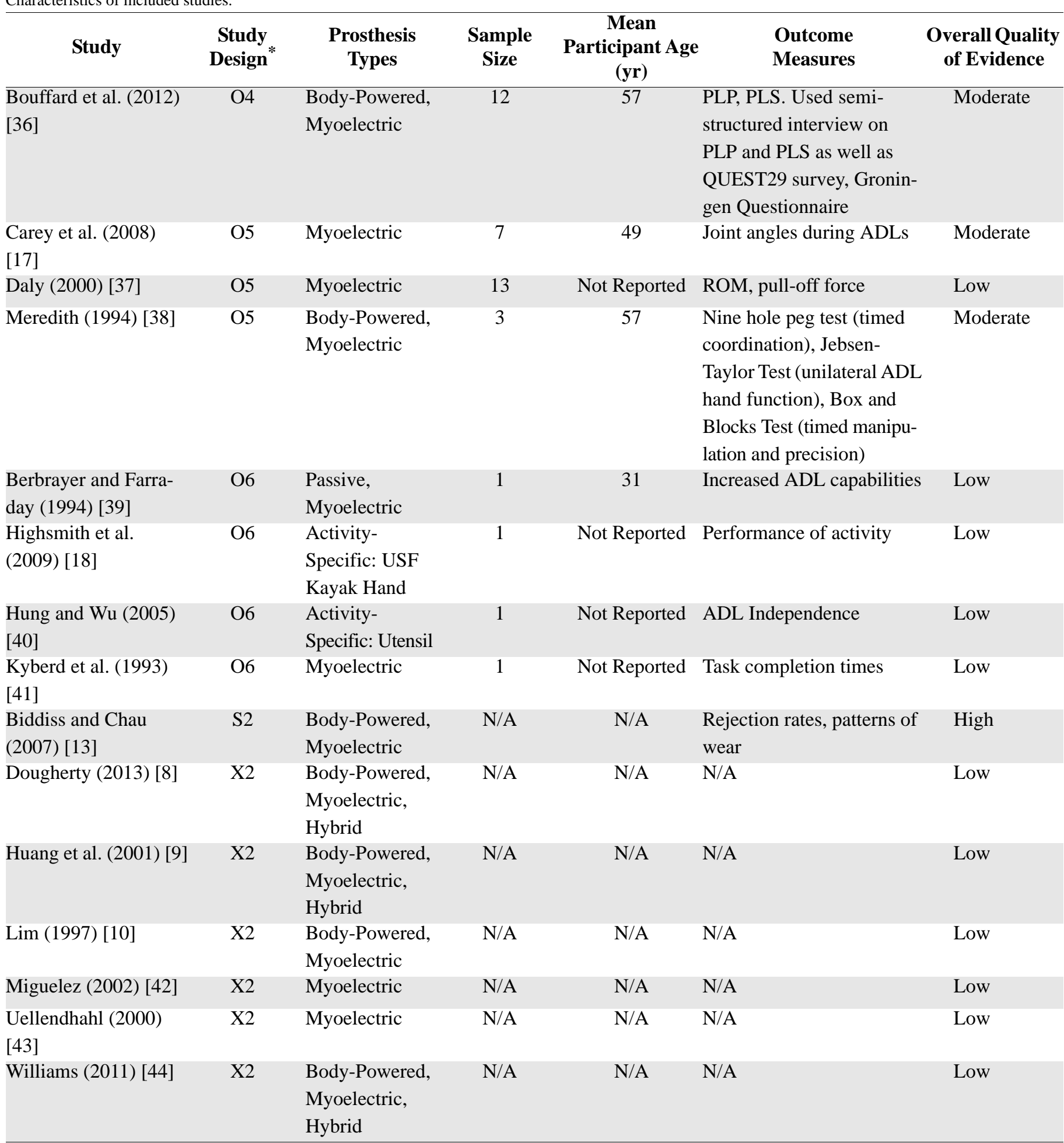

* Study design classification descriptions can be found in Table 2.

${ }^{\dagger}$ Study’s total sample number included persons with amputations that did not use prosthesis or rejected prosthesis after one use.

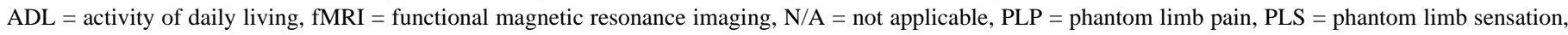

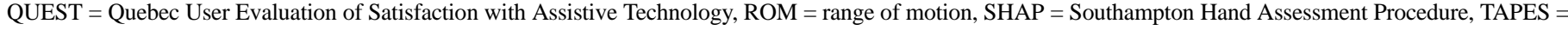
Trinity Amputation and Prosthesis Experience Scales, TD = terminal device, USF = University of South Florida. 
Table 2.

Distribution of included studies by study design.

\begin{tabular}{lc}
\hline \multicolumn{1}{c}{ Study Design } & $\begin{array}{c}\text { Number of } \\
\text { Publications }\end{array}$ \\
\hline Meta-Analysis (S1) & 0 \\
Systematic Review (S2) & 1 \\
Randomized Control Trial (E1) & 0 \\
Controlled Trial (E2) & 0 \\
Interrupted Time Series Trial (E3) & 0 \\
Single-Subject Trial (E4) & 2 \\
Controlled Before and After Trial (E5) & 3 \\
Cohort Study (O1) & 0 \\
Case-Control Study (O2) & 0 \\
Cross-Sectional Study (O3) & 11 \\
Qualitative Study (O4) & 1 \\
Case Series (O5) & 3 \\
Case Study (O6) & 4 \\
Group Consensus (X1) & 0 \\
Expert Opinion (X2) & 6 \\
\hline Total & 31 \\
\hline \hline
\end{tabular}

assessing upper-limb prostheses and accounted for 9 of the 24 relevant included articles. Kinematic evaluation of upper-limb prosthesis was the most common laboratory assessment and was used by Carey et al. [17,21] and Bouwsema et al. [28]. Bouwsema et al. also conducted the SHAP [28]. The nine hole peg test and Jebsen-Taylor test were conducted by Meredith [38], and a Box and Blocks test was conducted by Meredith [38] and Hebert and Lewicke [24]. Daly evaluated socket effect on ROM and socket pull-off force [37]. Kyberd et al. evaluated task completion times [41]. Kitayama et al. evaluated force required to open the terminal device (TD) at various elbow flexion angles and cable operating efficiency [26]. Lotze et al. analyzed functional magnetic resonance imaging (fMRI) to assess correlations with phantom limb pain and prostheses use [34]. Reported and observed ability to use prostheses to complete activities was also used to assess prostheses performance, and was used in 3 of the 24 relevant included articles. Berbrayer and Farraday reported an increase in ADL capabilities [39]. Highsmith et al. reported the successful design of a custom TD for kayaking [18]. Hung and Wu described increased independence in use of utensil prostheses for ADLs [40].

\section{Methodological Quality Assessment}

Of the included publications,18 were rated as "low," 11 were rated as "moderate," and 2 were rated as "high" for overall quality of assessment (Table 3). A number of threats to internal validity were prevalent in the studies, with the most common threats being not blinding intervention (IV-6) or not reporting effect size (IV-15). There were also a number of threats to external validity, the most common threats being sample characteristics not adequately described (EV-1) or conclusions not properly placed in context to existing literature (EV-7). One systematic review [13] was included and received a high quality rating using section 6 of the Sign 50 [22] methodology checklist. Six publications (Table 2) were expert opinions and were therefore give a low quality of evidence and were not included in the internal and external scoring shown in Table 3.

\section{Empirical Evidence Statements}

Eleven EESs were created based on the findings of the 31 included studies in order to address the areas of interests: functionality, control and feedback, cosmesis and psychosocial issues, and rejection. The EES statements were divided into the following five categories: activity/sport specific, body-powered, control, myoelectric, and rejection rates. The reviewers agreed on a level of confidence for each EES based on the accumulated supporting evidence for each statement. Table 4 shows the distribution of empirical evidence-based statements based on level of confidence, indicating that the majority of the statements were low and none were high.

\section{DISCUSSION}

The purpose of this systematic review was to identify and evaluate the body of literature that compared BP and MYO prostheses and to synthesize the knowledge obtained into clinically useful evidence. In this $21 \mathrm{yr}$ review period, 31 articles were available to support evidence statements regarding differences between MYO and BP prostheses. This is a crude publication rate of 1.5 articles per year, which does not seem considerably different from other areas of prosthetics and rehabilitation. Examples include a recent review of microprocessor knees that yielded 18 articles in a $14 \mathrm{yr}$ review period (crude rate of 1.3 articles/year) [45] or spinal rehabilitation that yielded 11 randomized trials in a 13 yr review period ( 0.8 trials per year) [46]. The difference is that the reviews on microprocessor knees and spinal rehabilitation were reviewing only very specific studies (i.e., comparative effectiveness only), whereas this review included all 
Table 3.

Internal and external validity of included studies.

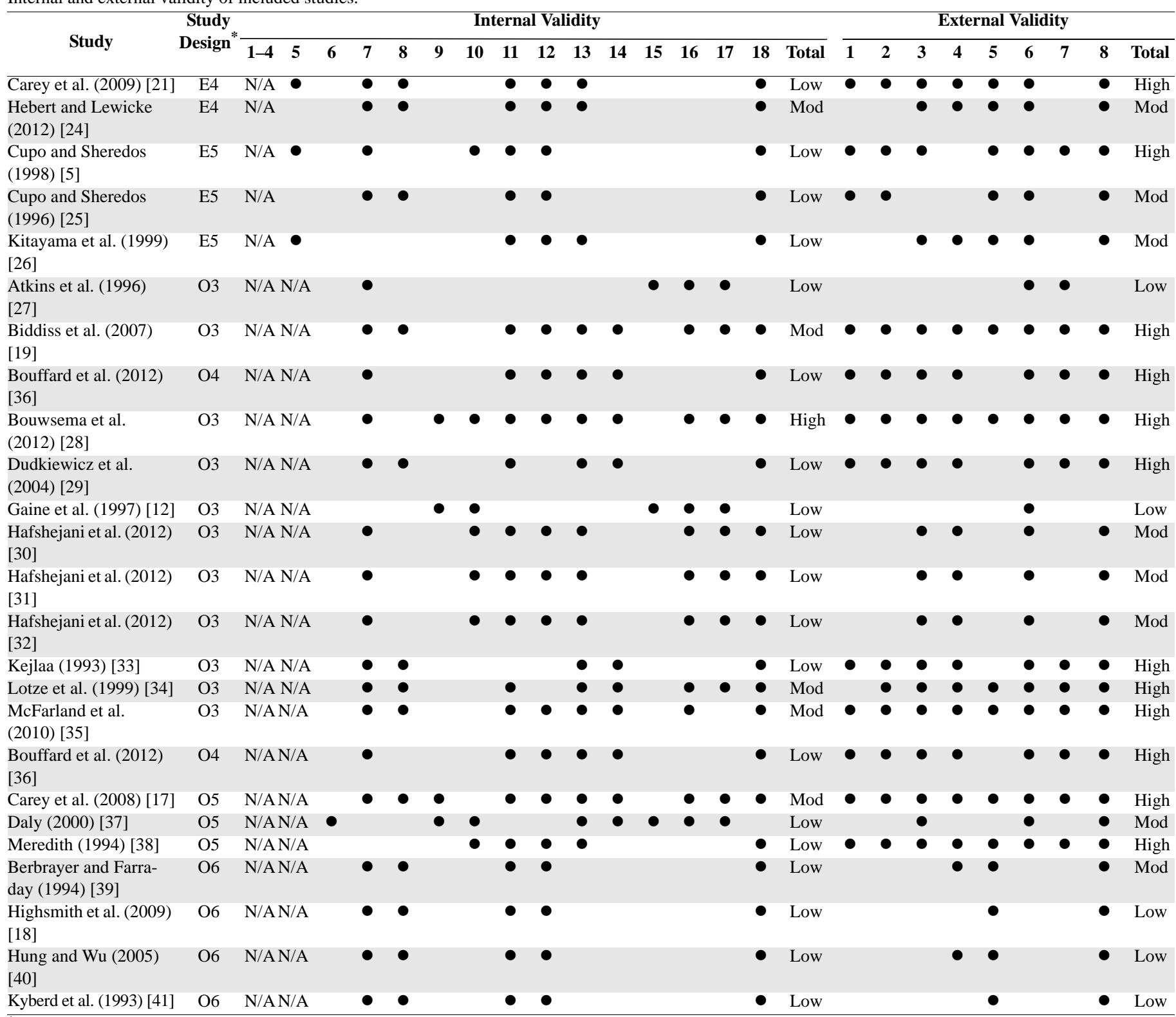

${ }^{*}$ Study design classification descriptions can be found in Table 2.

Mod $=$ moderate, $\mathrm{N} / \mathrm{A}=$ not applicable.

study design types as well as editorials. The experiments included in this $14 \mathrm{yr}$ review had a comparable publication rate of 0.2 articles/year, making the publication rate of upper-limb prostheses seem quite low.

\section{Task-Specific Upper-Limb Prostheses}

A statement regarding activity-specific prostheses was produced with regard to EESs available from the literature on the subjects of BP and MYO prostheses.
Despite the lower-quality evidence supporting the statement, activity-specific prostheses clearly have a role in athletic pursuits since persons with upper-limb amputation can successfully participate in athletic endeavors with the use of passive, specialized TDs. Ironically, while athletic TDs are generally passive, they can enable participation in high-demand, high-stress activities [18]. Further study would be useful to clarify whether an entirely specialized prosthesis (i.e., suspension, socket) would 
Table 4.

Empirical evidence statements

\begin{tabular}{|c|c|c|c|}
\hline Empirical Evidence Statement & Supporting Studies & $\begin{array}{c}\text { Level of } \\
\text { Confidence }\end{array}$ & Category \\
\hline $\begin{array}{l}\text { Activity-specific prostheses provide functional } \\
\text { advantage. }\end{array}$ & 2 Low $[18,40]$ & Low & $\begin{array}{l}\text { Activity/Sport- } \\
\text { Specific }\end{array}$ \\
\hline $\begin{array}{l}\text { Depending on functional needs, control scheme familiar- } \\
\text { ity and user preference, either BP prostheses with con- } \\
\text { ventional hook or MYO are advantageous compared } \\
\text { with each other or other alternatives. }\end{array}$ & $\begin{array}{l}5 \text { Low }[9-10,39,43-44] \\
5 \text { Moderate }[17,21,24,29,38]\end{array}$ & Moderate & $\mathrm{BP}$ \\
\hline $\begin{array}{l}\text { Compared with MYO prostheses, BP prostheses are } \\
\text { more durable, require shorter training time, require less } \\
\text { adjustments, are easier to clean, and function with less } \\
\text { sensitivity to fit. }\end{array}$ & 3 Low $[9,43-44]$ & Low & $\mathrm{BP}$ \\
\hline $\begin{array}{l}\text { BP prostheses provide more sensory feedback than MYO } \\
\text { prostheses. }\end{array}$ & 3 Low $[9,43-44]$ & Low & $\mathrm{BP}$ \\
\hline $\begin{array}{l}\text { Improvements in BP prosthetic operation may be made } \\
\text { within harness and cabling systems. }\end{array}$ & $\begin{array}{l}2 \text { Low }[5,26] \\
1 \text { Moderate [19] }\end{array}$ & Low & $\mathrm{BP}$ \\
\hline $\begin{array}{l}\text { Intuitive prosthetic control may require use of multiple } \\
\text { control strategies, such as BP, MYO, or hybrid, that } \\
\text { require less visual attention and ability to make coordi- } \\
\text { nated motions of two joints but should be evaluated for } \\
\text { each individual upper-limb prosthesis user. }\end{array}$ & $\begin{array}{l}5 \text { Low }[8,27,41,43-44] \\
2 \text { Moderate }[25,33] \\
1 \text { High }[28]\end{array}$ & Moderate & Control \\
\hline $\begin{array}{l}\text { Cosmesis is improved with MYO prosthesis over BP } \\
\text { prostheses. }\end{array}$ & $\begin{array}{l}3^{*} \text { Low }[9,30-32,43] \\
1 \text { Moderate }[38]\end{array}$ & Low & MYO \\
\hline $\begin{array}{l}\text { Prosthetic rehabilitation plan addressing critical factors } \\
\text { such as EMG site selection, controls and task training, } \\
\text { and comfort by cohesive team will improve function and } \\
\text { long-term success of electrically powered prosthesis } \\
\text { users. }\end{array}$ & 2 Low $[12,42]$ & Low & MYO \\
\hline $\begin{array}{l}\text { Roll-on sleeve improves suspension and increases range } \\
\text { of motion compared with self-suspending sockets. }\end{array}$ & 1 Low [37] & Insufficient & MYO \\
\hline $\begin{array}{l}\text { Regular MYO prosthetic use supports reduced cortical } \\
\text { reorganization and phantom-limb pain intensity. }\end{array}$ & 2 Moderate $[34,36]$ & Low & MYO \\
\hline $\begin{array}{l}\text { Proportion of rejections are not different between BP or } \\
\text { MYO prostheses. }\end{array}$ & 3 Moderate [13,19,35] & Insufficient & Rejection \\
\hline
\end{tabular}

improve success and participation level compared with adapting a BP or other multifunction prosthesis for the activity by exchanging the general-purpose TD with the specialized TD.

\section{Body-Powered Upper-Limb Prostheses}

Collectively, studies disagree as to whether BP or MYO prostheses are ultimately superior to one another functionally. For instance, users indicate BP prostheses are better suited for working conditions that include light sitting work or combined sitting/standing work but could also include exceedingly heavy work $[9,43]$. In contrast,
MYO prostheses tend to be used for only light work $[9,33]$. In specific tasks, MYO prostheses incorporating a hand reportedly offer the ability to handle larger-diameter objects and the ability to grasp small objects [9].

Ten studies of varying quality and design (Table 4) suggest that, depending on functional needs, control scheme familiarity, and user preference, either BP with a conventional hook or MYO prostheses are advantageous compared with each other or other alternatives [9$10,17,21,24,29,38-39,43-44]$. The range of study designs supporting this statement includes expert opinion, observational, and experimental designs. In the observational 
work by Kejlaa, it is reported that BP prostheses may be used for a larger range and a typically more demanding level of work than MYO and passive alternatives [33]. $\mathrm{BP}$ prostheses presently have a key role among users who may be involved with heavy work in unforgiving environments or among users who are generally more functionally minded and have less regard for cosmesis.

Evidence indicated that BP prostheses are more durable and require less training and fewer adjustments than externally powered alternatives. BP prostheses, further, are noted to be easier to clean and maintain functionality with less adverse effect to function in the presence of loss of fit. Confidence in this statement is low because it is supported by multiple expert opinion articles [9,43-44]; however, implications for this statement are considerable. BP hooks are also declared to be simple, robust, and well-suited for manual labor [43]. When healthcare costs are a factor, the facts that $\mathrm{BP}$ systems require less training and that they are more durable than alternatives also have appeal and can assure enhanced functionality with potentially less healthcare financial resources. Blough et al. projected costs over the lifespan of veterans who lost their upper limb(s) in service during the Vietnam war compared with veterans and servicemembers from Operation Iraqi Freedom/Operation Enduring Freedom (OIF/ OEF) [47]. They reported that upper-limb prosthetic costs over the lifespan for Vietnam veterans with unilateral upper-limb loss who owned and used $1.0 \pm 0.8$ devices at a time were $\$ 131,900$. Conversely, veterans from OIF/OEF who had unilateral upper-limb loss used $1.8 \pm 1.7$ devices at a time and had projected lifetime costs of $\$ 823,239$ for prosthetic care. These prosthetic projections are helpful but predicated on multiple assumptions and do not clarify the specific devices utilized. More recently, Resnik et al. reported externally powered upper-limb prostheses range in cost from $\$ 25,000$ to $\$ 75,000$, which is substantially higher than $\mathrm{BP}$ prostheses ranging from $\$ 4,000$ to $\$ 10,000$ [2]. Insurance reimbursement has also changed considerably in that time. Nevertheless, while these upper-limb prosthetic costs demonstrate that MYO prostheses are more expensive and require more training [9], a detailed healthcare economic analysis of upper-limb prosthetic costs related to both device provision and training is presently needed to clarify financial differences and the associated cumulative financial effect on the user.

Several experts independently attribute continued success of BP prostheses at least partially to improved feed- back related to operation of the device and its interaction with objects. BP users reportedly offer some positional information to users even in dim or no light conditions [44]. This is in contrast to externally powered systems whereby control is via myosignaling, which offers no feedback comparable to BP actuation, which tells the user how much a split hook is presently open. Proprioceptive feedback is another reported benefit of cableactuated devices whereby kinetic and kinematic data are exchanged between prosthesis and residual limb during manipulation [9,43]. An additional means of feedback associated with BP system use is visual information [9]. Visual feedback is the primary source of functional feedback during manipulation with a MYO prosthesis [43] but is one of many forms of feedback available to BP users. Some experts state that a BP prosthesis with a hook TD provides an unobstructed view of objects of interest $[44,48]$ and that the cable/harness system provides haptic feedback [43-44], allowing the user to sense the amount of opening of the hook. While all reporting experts seem to agree that BP prostheses ultimately improve sensory feedback, confidence in the associated evidence statement is low because all associated literature was ultimately via expert opinion. Controlled experimentation is needed to confirm these anecdotal experiences.

There is still room for functional improvement of BP systems. Biddiss et al. report that consumer design priorities for BP prosthesis users include improved comfort, reduced mass, and further functional enhancements [19]. Specifically in regard to function, users express desire for improved wrist movement and control, overall maneuverability, coordination, and sensory feedback. Other issues identified with BP systems include increased movement and task-completion time compared with the sound limb [6]. Although not specifically reported in literature, these additional gross body movements coupled with the need to utilize the same activation force regardless of task may lead to bodily injury over time. So, while BP systems currently prevail in the area of sensory feedback, users express interest in further improvements here. Finally, increased grasp force is also of interest for BP system users [19]. Despite users' interest in having improvements to BP systems in these areas, little advancement has been made recently. Kitayama et al. added a pulley in the cabling system of a BP prosthesis to decrease the TD opening force at different elbow positions and to enable full TD opening at larger elbow flexion angles [26]. A low-friction cable liner was also 
utilized to increase cable operating efficiency regardless of length of residuum or level of amputation. Collectively, these studies demonstrate that while there are certain functional benefits associated with BP prosthetic use, improvements are still necessary to maximize user's functionality and quality of life.

\section{Optimizing Upper-Limb Prosthetic Control}

Moderate evidence indicates that in order to improve intuitive prosthetic control, multiple control strategies may need to be implemented. Intuitive control strategies should require less visual attention, allow for coordinated motions of two joints, and should be evaluated for each individual prosthesis user. Experts suggest that MYO control or any other control scheme (i.e., BP, hybrid control) should not be deemed singularly optimal but rather one of several control options considered in clinical practice depending on patient attributes, goals, and functional needs [43]. According to experts, MYO control offers little proprioceptive feedback or information to the user regarding joint position, speed of movement, and grip force [43-44,49]. Conversely, when someone has already accepted a MYO prosthesis as their primary system, they tend to report improved sensory feedback, including proprioception, in connection with the prosthesis [14]. Williams states that users ultimately should not have to think about how to control their prostheses [44]. Davalli et al. describe early technological designs integrating tactile and thermal feedback for MYO prosthesis users [50]. Pattern recognition control systems that allow multiple movements have the potential to provide more reliable MYO prostheses via self-recalibration, improved maintenance, and increasing functional use time and wear [51]. Engeberg and Meek developed an enhanced visual feedback system for slip prevention, but it was only tested on nondisabled users, so it was not included in this systematic review [52]. This visually based slip detection system may add proprioception to future externally powered upper-limb prostheses. Both BP and MYO prosthesis users prioritize wrist movement, improved control mechanisms that require less visual attention, and the ability to make coordinated motions of two joints [27]. It is important to note that over 260 articles were excluded because of their focus on development of specific control algorithms or EMG processing but did not test these with actual prosthetic devices or prosthesis users.

\section{Myoelectric Powered Upper-Limb Prostheses}

MYO prostheses with hand TDs reportedly improve cosmesis compared with BP prostheses with hook TDs $[9,43]$. Other studies show that users concerned with cosmesis prefer a MYO prosthesis [31,38]. Silcox et al. reported that the highest percentage of persons with MYO systems used their prostheses in social situations more than users of BP and passive cosmetic systems [14]. MYO prosthesis users also reportedly have improved psychosocial and social adaptation compared with BP users [31], likely because of aesthetic design of MYO prostheses, which have greater resemblance to an anatomical upper limb. Also from a cosmetic perspective, BP prostheses include harness suspension systems with cable controls that can be visible through and damaging to the user's clothing in addition to irritating the axilla [9]. The combination of these factors may influence prosthetic choice for users concerned with cosmesis. With low confidence, reviewers agreed evidence supported the statement that cosmesis is improved with a MYO prosthesis.

Some experts also suggest that a prosthetic rehabilitation plan addressing critical factors such as EMG site selection, controls and task training, and comfort by a cohesive team will improve function and long-term success of electrically powered prosthesis users [12,42]. A questionnaire of 55 upper-limb prosthesis users [12] and an expert opinion [42] support this statement with low evidence. Others suggest that rehabilitation is vital to functional integration of upper-limb prostheses [10] and that the functional and psychological needs of the user and knowledge of prosthetic options are important to effectively manage an upper-limb amputation [7]. Dawson et al. developed a MYO training system that was tested on only five nondisabled subjects and emphasized the need for investigating the effect of training tools on clinical outcomes [53]. All this suggests that it is not just the prosthetic device itself that influences functionality, psychosocial issues, and rejection, but that a clinical team needs to work with the users on specific issues for optimal performance of a MYO prosthesis.

Phantom limb pain is any sensation in the amputated part of the arm that is perceived as painful [36,54]. Phantom limb pain may begin immediately postamputation and is problematically high, with an estimated 50 percent prevalence in persons with upper-limb amputation [15]. Phantom limb pain may be intense in affected persons with initial mean intensity as high as $3.8 \pm 2.3$ out of 6 
postamputation as measured with the multidimensional pain intensity scale [34,55]. In a sample of 14 persons with transradial amputation, Lotze et al. reported that frequent and extensive MYO prosthetic use, which includes muscular training, ongoing stimulation and visual feedback, might be beneficial both in limiting cortical reorganization and in reducing phantom limb pain [34]. Investigators postulated increased phantom pain causing decreased prosthesis use is unlikely because no patient reported increased phantom pain with prosthetic use or cited pain as a reason for prosthetic discontinuance. Using qualitative and survey methodologies, Bouffard et al. evaluated a sample of 12 persons with upperlimb amputation (85\% transradial, 15\% transhumeral) [36]. Their findings were not in agreement with those of Lotze et al. regarding strictly beneficial effects of prosthetic use, specifically MYO use, relative to phantom limb pain. That is, most subjects in their study reported that increased prosthetic use resulted in increased phantom limb pain. This disagreement in findings may be partially due to differences in the type of prostheses used. The Bouffard et al. study was of the $\mathrm{O} 4$ category and the Lotze et al. study was of a higher study design category (O3). Further, the Lotze et al. study used robust outcome measures (i.e., fMRI and West Haven-Yale Multidimensional Pain Inventory) and achieved statistically significant differences to support their conclusions. Both studies were of moderate quality but disagreed in their conclusions. Ultimately, both conclusions suggest some effect of MYO prosthetic use on phantom pain.

Although not mentioned in the literature, users may prefer MYO prostheses in the near future with improvements in the shape and articulations of prosthetic hands as well as improved connections to the neuromusculoskeletal networks. The use of a MYO prosthesis may also provide an exercise regimen for overall upper-limb health over time.

\section{Differences in Rejection Between Body-Powered and Myoelectric Prostheses}

Rejection of upper-limb prostheses is a complex issue. Biddiss and Chau suggested an enormous pitfall facing upper-limb prosthetic developers, potentially contributing to rejection, is the desire to design prosthetic componentry with emerging technologies in advance of clearly defining the needs and desires of upper-limb prosthesis users [13]. Users may reject an upper-limb prosthesis for a multitude of reasons [35]. The overall mean rejec- tion rate from 22 studies associated with MYO prosthetic use was 23 percent (range: $0 \%-75 \%$ ) [13]. Reasons for rejecting MYO prostheses included issues related to mass, wear temperature, durability, reliability, and increased reliance on visual attention [35]. BP upperlimb prostheses, seemingly more popular in the United States than other countries presently, continue to be a popular choice for initial fittings and long-term use. The overall mean rejection rate for $\mathrm{BP}$ prostheses reported from 11 studies was 26 percent (range: 16\%-66\%) [13]. Some evidence suggests that rejection of BP systems with a hand TD may be as high as 80 to 87 percent $[33,56]$. Reasons cited for the higher rejection of BP hand TDs include slower movement, poor grasp force, increased mass, and energy expense for operation. Conversely, BP hook TDs remain popular for their functionality, durability, low mass, and improved visual access to objects of interest during manipulation $[9,13,43]$. Despite the considerable differences in BP TDs, BP prostheses are generally associated with user complaints including increased wearing temperature, clothing damage, poor cosmesis, and cable and harness maintenance issues. From their review of $25 \mathrm{yr}$ of literature, Biddiss and Chau ultimately concluded there was no difference in rejection rates between BP and MYO prostheses among adults [13]. In disagreement with this conclusion, however, a study of 242 upper-limb prosthesis users of varied etiology, demographics, and prosthetic use experiences resulted in different rejection rates. In this study, rejection was 50 percent among BP prosthesis users compared with 39 percent among MYO and hybrid systems [19]. McFarland et. al. reported 57 percent of veterans with amputation surveyed that rejected a prosthesis, used a MYO or hybrid control, compared with 40 percent who used a BP system [35]. These are considerably different rates of rejection than those reported from the systematic review of $25 \mathrm{yr}$ of literature $[13,19]$. Because of this disagreement, evidence supporting the conclusion that rejection is similar between $\mathrm{BP}$ and MYO prostheses is presently insufficient, thereby warranting further investigation. Future research should address the role of interface design and fabrication on upper-limb prosthetic function, rejection rates, and cosmesis.

\section{Limitations}

Due to the later introduction of MYO systems relative to BP systems, there was earlier familiarity and a predominance of BP systems that is not readily 
accounted for in the articles available in this review. Moreover, given the increase in publications in recent years, it seems that perhaps more funding may be catalyzing research and development in the area of upper-limb prosthetics. Thus, rapid development could have a transformative effect on this area of practice, necessitating further literature review sooner rather than later. Nevertheless, limitations to this systematic review must be considered. For instance, given the low number of controlled experiments, all study designs had to be included, which decreases the confidence in many of the evidence statements. Related to this issue, the high number of observational studies increased the external validity but threatens the internal validity of this body of literature on the subject of differences between BP and MYO prostheses. One approach would be to consider including more years of literature, but the consistency of practice and technology is questionable if such an approach is taken. Finally, in order to have a more focused set of evidence statements, this review elected to exclude bilateral and pediatric care because clinical management of these groups of patients is different and merit separate investigation.

\section{CONCLUSIONS}

This report is a systematic review of publications related to upper-limb prostheses with the goal of identifying evidence comparing currently available MYO and BP prosthetic devices. Eleven EESs were generated addressing the areas of interest: control, function, feedback, cosmesis, and rejection. Conflicting evidence has been found in terms of the relative functional performance of BP and MYO prostheses. Several specific domains have been established that show advantages of each type of prosthesis. Activity-specific passive and BP prostheses can provide significant advantages to prostheses users and are typically lower cost than alternatives. BP prostheses have been shown to have advantages in durability; training time; and frequency of adjustment, maintenance, and feedback. Some evidence demonstrated BP prosthetic control can be improved by optimizing harness and cabling systems. MYO prostheses have been shown to provide a cosmetic advantage, are more accepted for light-intensity work, and may positively affect phantom limb pain when used actively. MYO prostheses can be improved with more advanced control methods; however, there is little evidence of these methods transition- ing into larger controlled studies and further into clinical practice.

Outside of surveys, there is little evidence addressing the functional capabilities of prostheses users and fewer studies making a direct comparison of prostheses in a controlled setting. A few standardized tests to directly evaluate prostheses function were found in multiple studies. Currently, evidence is insufficient to conclude that either the current generation of a MYO or a BP prosthesis provides a significant general advantage. Selection of a prosthesis should be made based on a patient's individual needs with regard to domains where differences have been identified. A patient's personal preferences, prosthetic experience, and functional needs are all important factors to consider. This work demonstrates that there is a lack of empirical evidence regarding functional differences in upper-limb prostheses.

\section{ACKNOWLEDGMENTS}

\section{Author Contributions:}

Study concept and design: S. L. Carey. Acquisition of data: D. J. Lura, M. J. Highsmith.

Drafting of manuscript: S. L. Carey, D. J. Lura, M. J. Highsmith. Critical revision of manuscript for important intellectual content: D. J. Lura, M. J. Highsmith.

Financial Disclosures: The authors have declared that no competing interests exist.

Funding/Support: This material was based on work supported by the AAOP.

\section{REFERENCES}

1. Ziegler-Graham K, MacKenzie EJ, Ephraim PL, Travison TG, Brookmeyer R. Estimating the prevalence of limb loss in the United States: 2005 to 2050. Arch Phys Med Rehabil. 2008;89(3):422-29. [PMID:18295618]

http://dx.doi.org/10.1016/j.apmr.2007.11.005

2. Resnik L, Meucci MR, Lieberman-Klinger S, Fantini C, Kelty DL, Disla R, Sasson N. Advanced upper limb prosthetic devices: Implications for upper limb prosthetic rehabilitation. Arch Phys Med Rehabil. 2012;93(4):710-17. [PMID:22464092] http://dx.doi.org/10.1016/j.apmr.2011.11.010

3. Kruger LM, Fishman S. Myoelectric and body-powered prostheses. J Pediatr Orthop. 1993;13(1):68-75.

[PMID:8416358]

http://dx.doi.org/10.1097/01241398-199301000-00014 
4. Pezzin LE, Dillingham TR, Mackenzie EJ, Ephraim P, Rossbach P. Use and satisfaction with prosthetic limb devices and related services. Arch Phys Med Rehabil. 2004; 85(5):723-29. [PMID:15129395] http://dx.doi.org/10.1016/j.apmr.2003.06.002

5. Cupo ME, Sheredos SJ. Clinical evaluation of a new, above-elbow, body-powered prosthetic arm: A final report. J Rehabil Res Dev. 1998;35(4):431-46. [PMID:10220222]

6. Doeringer JA, Hogan N. Performance of above elbow body-powered prostheses in visually guided unconstrained motion tasks. IEEE Trans Biomed Eng. 1995;42(6):621-31. [PMID:7790019] http://dx.doi.org/10.1109/10.387202

7. Behrend C, Reizner W, Marchessault JA, Hammert WC. Update on advances in upper extremity prosthetics. J Hand Surg Am. 2011;36(10):1711-17. [PMID:21971060] http://dx.doi.org/10.1016/j.jhsa.2011.07.024

8. Dougherty PJ. Research and future developments in upper and lower limb prostheses. Curr Orthop Pract. 2013;24(2): 149-52. http://dx.doi.org/10.1097/BCO.0b013e31827f5a82

9. Huang ME, Levy CE, Webster JB. Acquired limb deficiencies. 3. Prosthetic components, prescriptions, and indications. Arch Phys Med Rehabil. 2001;82(3 Suppl 1):S17-24. [PMID:11239332] http://dx.doi.org/10.1016/S0003-9993(01)80032-0

10. Lim PA. Advances in prosthetics: A clinical perspective. Phys Med Rehabil. 1997;11(1):13-38.

11. Wright TW, Hagen AD, Wood MB. Prosthetic usage in major upper extremity amputations. J Hand Surg Am. 1995;20(4):619-22. [PMID:7594289] http://dx.doi.org/10.1016/S0363-5023(05)80278-3

12. Gaine WJ, Smart C, Bransby-Zachary M. Upper limb traumatic amputees. Review of prosthetic use. J Hand Surg [Br]. 1997;22(1):73-76. [PMID:9061532] http://dx.doi.org/10.1016/S0266-7681(97)80023-X

13. Biddiss EA, Chau TT. Upper limb prosthesis use and abandonment: A survey of the last 25 years. Prosthet Orthot Int. 2007;31(3):236-57. [PMID:17979010] http://dx.doi.org/10.1080/03093640600994581

14. Silcox DH 3rd, Rooks MD, Vogel RR, Fleming LL. Myoelectric prostheses. A long-term follow-up and a study of the use of alternate prostheses. J Bone Joint Surg Am. 1993;75(12):1781-89. [PMID:8258548]

15. Biddiss E, Chau T. Upper-limb prosthetics: Critical factors in device abandonment. Am J Phys Med Rehabil. 2007; 86(12):977-87. [PMID:18090439] http://dx.doi.org/10.1097/PHM.0b013e3181587f6c

16. Bertels T, Schmalz T, Ludwigs E. Objectifying the functional advantages of prosthetic wrist flexion. J Prosthet Orthot. 2009;21(2):74-78. http://dx.doi.org/10.1097/JPO.0b013e3181a10f46
17. Carey SL, Highsmith JM, Maitland ME, Dubey RV. Compensatory movements of transradial prosthesis users during common tasks. Clin Biomech (Bristol, Avon). 2008;23 (9):1128-35. [PMID:18675497] http://dx.doi.org/10.1016/j.clinbiomech.2008.05.008

18. Highsmith MJ, Carey SL, Koelsch KW, Lusk CP, Maitland ME. Design and fabrication of a passive-function, cylindrical grasp terminal device. Prosthet Orthot Int. 2009; 33(4):391-98. [PMID:19961298] http://dx.doi.org/10.3109/03093640903241771

19. Biddiss E, Beaton D, Chau T. Consumer design priorities for upper limb prosthetics. Disabil Rehabil Assist Technol. 2007;2(6):346-57. [PMID:19263565] http://dx.doi.org/10.1080/17483100701714733

20. Hafner B. AAOP state-of-the-science evidence report guidelines. Washington (DC): American Academy of Orthotists and Prosthetists; 2008.

21. Carey SL, Dubey RV, Bauer GS, Highsmith MJ. Kinematic comparison of myoelectric and body powered prostheses while performing common activities. Prosthet Orthot Int. 2009;33(2):179-86. [PMID:19367522] http://dx.doi.org/10.1080/03093640802613229

22. SIGN 50: A guideline developer's handbook. Edinburgh (UK): Scottish Intercollegiate Guidelines Network; 2013.

23. Sawers AB, Hafner BJ. Outcomes associated with the use of microprocessor-controlled prosthetic knees among individuals with unilateral transfemoral limb loss: A systematic review. J Prosthet Orthot. 2013;50(3):273-314.

[PMID:23881757]

http://dx.doi.org/10.1682/JRRD.2011.10.0187

24. Hebert JS, Lewicke J. Case report of modified Box and Blocks test with motion capture to measure prosthetic function. J Rehabil Res Dev. 2012;49(8):1163-74. [PMID:23341309] http://dx.doi.org/10.1682/JRRD.2011.10.0207

25. Cupo ME, Sheredos SJ. Clinical evaluation of the Modular Electromechanical Lock Actuator (MELA) for aboveelbow prostheses: A final report. J Rehabil Res Dev. 1996;33(1):56-67. [PMID:8868418]

26. Kitayama I, Matsuda M, Nakajima S, Sawamura S, Ninomiya H, Furukawa H. Improvement of control cable system of trans-humeral body-powered prostheses. Prosthet Orthot Int. 1999;23(2):123-29. [PMID:10493139]

27. Atkins DJ, Heard DC, Donovan WH. Epidemiologic overview of individuals with upper-limb loss and their reported research priorities. J Prosthet Orthot. 1996;8(1):2-11. http://dx.doi.org/10.1097/00008526-199600810-00003

28. Bouwsema H, Kyberd PJ, Hill W, van der Sluis CK, Bongers RM. Determining skill level in myoelectric prosthesis use with multiple outcome measures. J Rehabil Res Dev. 2012;49(9):1331-48. [PMID:23408215] http://dx.doi.org/10.1682/JRRD.2011.09.0179 
29. Dudkiewicz I, Gabrielov R, Seiv-Ner I, Zelig G, Heim M. Evaluation of prosthetic usage in upper limb amputees. Disabil Rehabil. 2004;26(1):60-63. [PMID:14660200] http://dx.doi.org/10.1080/09638280410001645094

30. Hafshejani MK, Naeini MS, Langari A. On the functional limitation in below elbow amputation men using Mechanical and Myoelectric prosthesis via TAPES questionnaire. Life Sci J. 2012;9(4):5579-82.

31. Hafshejani MK, Javanshir M, Kamali M, Ghasemi MS, Emami M, Esmaeeli SA, Langari A, Sattari Naeini M. The comparison of psychological and social adaptation below elbow amputation men using a mechanical and myoelectric prosthesis by using of TAPES questionnaire. Life Sci J. 2012;9(4):5583-87.

32. Hafshejani MK, Naeini MS, Langari A. The comparison of satisfaction of prosthesis in below amputation men using a mechanical and Myoelectric prosthesis by using of TAPES questionnaire. Life Sci J. 2012;9(4):5588-92.

33. Kejlaa GH. Consumer concerns and the functional value of prostheses to upper limb amputees. Prosthet Orthot Int. 1993;17(3):157-63. [PMID:8134275]

34. Lotze M, Grodd W, Birbaumer N, Erb M, Huse E, Flor H. Does use of a myoelectric prosthesis prevent cortical reorganization and phantom limb pain? Nat Neurosci. 1999; 2(6):501-2. [PMID:10448212] http://dx.doi.org/10.1038/9145

35. McFarland LV, Hubbard Winkler SL, Heinemann AW, Jones M, Esquenazi A. Unilateral upper-limb loss: Satisfaction and prosthetic-device use in veterans and servicemembers from Vietnam and OIF/OEF conflicts. J Rehabil Res Dev. 2010;47(4):299-316. [PMID:20803400] http://dx.doi.org/10.1682/JRRD.2009.03.0027

36. Bouffard J, Vincent C, Boulianne É, Lajoie S, Mercier C. Interactions between the phantom limb sensations, prosthesis use, and rehabilitation as seen by amputees and health professionals. J Prosthet Orthot. 2012;24(1):25-33. http://dx.doi.org/10.1097/JPO.0b013e318240d171

37. Daly W. Clinical application of roll-on sleeves for myoelectrically controlled transradial and transhumeral prostheses. J Prosthet Orthot. 2000;12(3):88-91. http://dx.doi.org/10.1097/00008526-200012030-00005

38. Meredith JM. Comparison of three myoelectrically controlled prehensors and the voluntary-opening split hook. Am J Occup Ther. 1994;48(10):932-37. [PMID:7825710] http://dx.doi.org/10.5014/ajot.48.10.932

39. Berbrayer D, Farraday WT. Switch-activated electrically controlled prosthesis following a closed head injury: A case study. J Prosthet Orthot. 1994;6(2):48-51.

40. Hung JW, Wu YH. Fitting a bilateral transhumeral amputee with utensil prostheses and their functional assessment 10 years later: A case report. Arch Phys Med Rehabil.
2005;86(11):2211-13. [PMID:16271573]

http://dx.doi.org/10.1016/j.apmr.2005.04.021

41. Kyberd PJ, Mustapha N, Carnegie F, Chappell PH. A clinical experience with a hierarchically controlled myoelectric hand prosthesis with vibro-tactile feedback. Prosthet Orthot Int. 1993;17(1):56-64. [PMID:8337101] http://dx.doi.org/10.3109/03093649309164355

42. Miguelez JM. Critical factors in electrically powered upper-extremity prosthetics. J Prosthet Orthot. 2002;14(1): 36-38. http://dx.doi.org/10.1097/00008526-200203000-00010

43. Uellendahl JE. Upper extremity myoelectric prosthetics. Phys Med Rehabil Clin N Am. 2000;11(3):639-52.

[PMID:10989484]

44. Williams TW 3rd. Progress on stabilizing and controlling powered upper-limb prostheses. J Rehabil Res Dev. 2011; 48(6):ix-xix. [PMID:21938646] http://dx.doi.org/10.1682/JRRD.2011.04.0078

45. Highsmith MJ, Kahle JT, Bongiorni DR, Sutton BS, Groer S, Kaufman KR. Safety, energy efficiency, and cost efficacy of the C-Leg for transfemoral amputees: A review of the literature. Prosthet Orthot Int. 2010;34(4):362-77.

[PMID:20969495]

http://dx.doi.org/10.3109/03093646.2010.520054

46. Lu Y, Guzman JZ, Purmessur D, Iatridis JC, Hecht AC, Qureshi SA, Cho SK. Nonoperative management of discogenic back pain: a systematic review. Spine. 2014; 39(16):1314-24.

47. Blough DK, Hubbard S, McFarland LV, Smith DG, Gambel JM, Reiber GE. Prosthetic cost projections for servicemembers with major limb loss from Vietnam and OIF/OEF. J Rehabil Res Dev. 2010;47(4):387-402.

[PMID:20803406]

http://dx.doi.org/10.1682/JRRD.2009.04.0037

48. McHugh S. A case for body-powered hooks. InMotion. 2010;20(3):21-22.

49. Zlotolow DA, Kozin SH. Advances in upper extremity prosthetics. Hand Clin. 2012;28(4):587-93.

[PMID:23101609]

http://dx.doi.org/10.1016/j.hcl.2012.08.014

50. Davalli A, Sacchetti R, Fanin S, Avanzolini G, Urbano E. Biofeedback for upper limb myoelectric prostheses. Technol Disabil. 2000;13(3):161-72.

51. Simon AM, Lock BA, Stubblefield KA. Patient training for functional use of pattern recognition-controlled prostheses. J Prosthet Orthot. 2012;24(2):56-64. [PMID:22563231] http://dx.doi.org/10.1097/JPO.0b013e3182515437

52. Engeberg ED, Meek S. Enhanced visual feedback for slip prevention with a prosthetic hand. Prosthet Orthot Int. 2012;36(4):423-29. [PMID:22402709] http://dx.doi.org/10.1177/0309364612440077 
53. Dawson MR, Fahimi F, Carey JP. The development of a myoelectric training tool for above-elbow amputees. Open Biomed Eng J. 2012;6:5-15. [PMID:22383905]

54. Kooijman CM, Dijkstra PU, Geertzen JH, Elzinga A, van der Schans CP. Phantom pain and phantom sensations in upper limb amputees: An epidemiological study. Pain. 2000;87(1):33-41. [PMID:10863043]

http://dx.doi.org/10.1016/S0304-3959(00)00264-5

55. Kerns RD, Turk DC, Rudy TE. The West Haven-Yale MultiDimensional Pain Inventory (WHYMPI). Pain. 1985;23(4): 345-56. [PMID:4088697]

http://dx.doi.org/10.1016/0304-3959(85)90004-1

56. Millstein SG, Heger H, Hunter GA. Prosthetic use in adult upper limb amputees: A comparison of the body powered and electrically powered prostheses. Prosthet Orthot Int. 1986;10(1):27-34. [PMID:3725563]
Submitted for publication August 26, 2014. Accepted in revised form February 12, 2015.

This article and any supplementary material should be cited as follows:

Carey SL, Lura DJ, Highsmith MJ. Differences in myoelectric and body-powered upper-limb prostheses: Systematic literature review. J Rehabil Res Dev. 2015;52(3): 247-62.

http://dx.doi.org/10.1682/JRRD.2014.08.0192

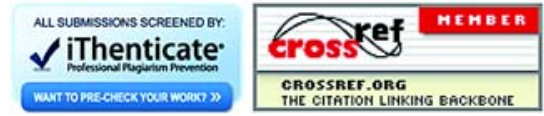

